\title{
A Large-scale Field Study on 3G Wireless Networks
}

\author{
Jingwen Liu ${ }^{\dagger *}$, Jin Teng*, Weidong Wang ${ }^{\dagger}$, Yinghai Zhang ${ }^{\dagger}$ \\ $\dagger$ Information \& Electronics Technology Lab, Beijing University of Posts and Telecommunications, P. R. China, 100876 \\ $*$ Department of Computer Science \& Engineering, The Ohio State University, OH, USA, 43210 \\ \{liujing,tengj\}@cse.ohio-state.edu, \{wangweidong,yhzhang\}@bupt.edu.cn
}

\begin{abstract}
There are four integral modules in a Cyber-Physical Networking System (CPNS): sensing, communication, decision, actuating. Among them, the communication module plays the vital role of central liaison. It glues everything together and orchestrates the operation of the whole system. Nowadays, local communications are not enough for practical CPNSs which can be very large in geographical scale. Such CPNSs require reliable and fast communication channels over a long distance. The 3G cellular networks provide a convenient and mature way. However, as different standards compete for dominance in the $\mathbf{3 G}$ market, it is necessary for us to gain a thorough understanding of the empirical performance for each of the standards. In this paper, we have conducted a large-scale empirical field study on 3G mobile systems performance in China. From the results, we have confirmed that the performance of $3 \mathrm{G}$ is largely satisfactory, especially in indoor environments and for high rate data services. On the other hand, we have made some unexpected new findings, which are helpful to improve the 3G system, especially the TDSCDMA networks, to better serve the needs of practical large CPNSs.
\end{abstract}

Index Terms-measurement; communications; 3G; TDSCDMA; service

\section{INTRODUCTION}

A cyber-physical system (CPS) is a system featuring a tight combination of, and coordination between, the system's computational and physical elements [1]. Unlike other traditional embedded systems, a full-fledged CPS is typically designed as a network of interacting elements with physical input and output instead of as standalone devices [2]. With the technologies of CPNSs, people could easily get the detailed information of a system far away with flexibility and convenience. One vital part of CPNSs is communications, which serves as a center pivot and directly affects the information exchange. Recently, the most widely adopted communication system is the 3rd generation (3G) cellular systems. Besides supporting voice, text and SMS (Short Message Service) services, 3G fulfills the increasing demand of multimedia and high bitrate data services [3], e.g., UMTS offers data rate up to $384 \mathrm{kbps}$ along with voice services [4]. $3 \mathrm{G}$ has been serving many regions and countries to support broadband communications. In other words, 3G wireless system is considered a much favored means of information exchange for large-scale CPNSs.

China has become the world's largest mobile market in terms of the subscriber number [5]. This number has jumped to 800 million by the end of 2010. Therefore, we take China as the testing target country. In China, there are three standards of $3 \mathrm{G}$ in commercial use. They are TD-SCDMA (Time Division Synchronous Code Division Multiple Access), WCDMA
(Wideband Code Division Multiple Access) and CDMA2000 (Code Division Multiple Access 2000) [6]. Among them, TDSCDMA was proposed by the China Wireless Technology Standard (WTS) Group and accepted as a 3rd Generation Standard for mobile radio applications [7]. China Mobile has provided TD-SCDMA service in most parts of China. Full coverage will be realized in 2011. Nevertheless, compared to GSM, WCDMA and CDMA2000, TD-SCDMA system is still young. It needs further improvement.

$3 \mathrm{G}$ technologies can provide real-time communications for multimedia application in large area networks, which is very difficult for Internet [8]. In order to achieve optimal performance of $3 \mathrm{G}$ networks, there are many researches on $3 \mathrm{G}$ performance measurement, but they either concern themselves with only one particular type of cellular network, or merely focus on a limited number of $3 \mathrm{G}$ features. The empirical study of the relationship between social network and $3 \mathrm{G}$ network is introduced in [9]. In [10], the authors perform the throughput and coverage studies of $3 \mathrm{G}$ networks, but the performance evaluation remains highly unclear for common services such as voice call, video call, data service and SMS. Similar work has been done in Hongkong [11], but only HSDPA is involved in the study. Hence, there is a need for an extensive empirical study for all $3 \mathrm{G}$ networks and their services.

One point to mention is that the measurement is administrated by a third party without commission from any operators. So the results are objective and credible. Our measurements are taken in five cities, distributed in different areas of China. To study the performance of $3 \mathrm{G}$, we examine the general service quality. These services under investigation are voice call, video call, data transmission, SMS. Through investigating and analyzing the data we collected, we get the following new findings:

-From the data of four services, we observed indoor performance is better than outdoor on voice service. As outdoor measurement is from driving tests, fast movement can cause changeable wireless environment which leads to performance degradation of $3 \mathrm{G}$. What is more, considering the attenuation of indoor environment, operators have established repeaters in the building to enhance the signal strength.

-In terms of high speed downloading for data services, WCDMA is far the best, based on the existing CDMA infrastructure. That means a lot of work should be done to improve the TD-SCDMA system.

-A common view is that the SMS success rate of reception is very high, even up to $100 \%$, since SMS does not have 
strict requirements on the infrastructure. But the result shows to us SMS performance is not satisfactory. It has exposed a misunderstanding commonly held for SMS.

In short, we have collected solid amount of data on different services from 5 cities and conducted a large scale empirical study. First, we confirmed that $3 \mathrm{G}$ system provides an eligible communication platform for CPNSs. Secondly, we compared 3 types of $3 \mathrm{G}$ standards, obtained the differences between TD and the others. Our findings are helpful to improve the TD-SCDMA system and spread TD-LTE system. The last but not the least, we realized evaluation of $3 \mathrm{G}$ system. Our measurement and analysis are useful for increasing $3 \mathrm{G}$ network capability to reach users' demands.

The rest of this paper is organized as follows. The background of 3G is introduced in Section 2. In Section 3, the measurement methodology is described. The analysis and explanations of the data are shown in Section 4. Finally, the conclusions are drawn in Section 5.

\section{BACKGROUND}

As is known to all, three 3G standard licenses have been awarded by Ministry of Industry and Information Technology of China and radio frequencies have been allocated. The largest mobile operator, China Mobile, gets TD-SCDMA standard, China Unicom has WCDMA standard, while CDMA2000 goes to China Telecom. It means that China has three main $3 \mathrm{G}$ standards in commercial use. Therefore, these three 3G standards are key points that we study:

-TD-SCDMA: TD-SCDMA represents Time Division Synchronous Code Division Multiple Access, an air interface found in UMTS mobile telecommunications networks [12]. It was commercialized in 2009 and is only offered in China. This scheme of TD-SCDMA uses the existing GSM infrastructure with 3rd generation service availability. Unlike WCDMA and CDMA2000, which adopt frequency-division duplex (FDD), TD-SCDMA is designed for time-division duplex/multiple access (TDD/TDMA). Unlike FDD requires the allocation of symmetric frequency resources, the system can easily accommodate asymmetric traffic with different data rate requirements on downlink and uplink. It made flexible utilization of available frequencies. Moreover, using the same carrier frequency for uplink and downlink means that the channel condition is the same on both directions. Base station can deduce the downlink channel information from uplink channel estimates, which is helpful to relieve the load of the channel.

-WCDMA: WCDMA (Wideband Code Division Multiple Access) is an air interface for one of the ITU's (International Telecommunications Union's) standards [13]. It includes many of the basic subsystems of GSM. The world's first commercial W-CDMA service, FOMA, was launched by NTT DoCoMo in Japan in 2001 [14]. It is mainly used in Europe in the context of migration from GSM to UMTS as the radio access scheme used for third generation cellular systems.
TABLE I

KEY PARAMETERS OF THE THREE MAIN 3G STANDARDS

\begin{tabular}{|l|l|l|l|}
\hline & CDMA2000 & WCDMA & TD-SCDMA \\
\hline $\begin{array}{l}\text { Carrier } \\
\text { Bandwidth }\end{array}$ & $\begin{array}{l}\text { Paired, } \\
1.25 / 3.75 \mathrm{MHz}\end{array}$ & Paired, 5MHz & $\begin{array}{l}\text { Unpaired, } \\
1.6 \mathrm{MHz}\end{array}$ \\
\hline $\begin{array}{l}\text { Multiple } \\
\text { Access }\end{array}$ & $\begin{array}{l}\text { DS-CDMA } \\
\text { /MC-CDMA }\end{array}$ & DS-CDMA & $\begin{array}{l}\text { TDMA /DS- } \\
\text { CDMA }\end{array}$ \\
\hline $\begin{array}{l}\text { Data } \\
\text { Modulation }\end{array}$ & $\begin{array}{l}\text { DL:QPSK, } \\
\text { UL:BPSK }\end{array}$ & $\begin{array}{l}\text { DL:QPSK, } \\
\text { UL:BPSK }\end{array}$ & $\begin{array}{l}\text { QPSK,8-PSK } \\
\text { (optional) }\end{array}$ \\
\hline $\begin{array}{l}\text { Maximum } \\
\text { Data-rate }\end{array}$ & $\begin{array}{l}2.4 \mathrm{Mb} / \mathrm{s} \\
(1 \mathrm{xEV}-\mathrm{DO})\end{array}$ & $2 \mathrm{Mb} / \mathrm{s}$ & $2 \mathrm{Mb} / \mathrm{s}$ \\
\hline Efficiency & 1.0 & 0.4 & 1.25 \\
\hline Power Control & $\begin{array}{l}\text { Open and fast } \\
\text { closed loop } \\
(800 \mathrm{~Hz})\end{array}$ & $\begin{array}{l}\text { Open and fast } \\
\text { closed loop } \\
(1600 \mathrm{~Hz})\end{array}$ & $\begin{array}{l}\text { Open and fast } \\
\text { closed loop } \\
(200 \mathrm{~Hz})\end{array}$ \\
\hline $\begin{array}{l}\text { Inter-BS } \\
\text { Timing }\end{array}$ & $\begin{array}{l}\text { GPS } \\
\text { synchronous }\end{array}$ & $\begin{array}{l}\text { Asynchronous/ } \\
\text { synchronous }\end{array}$ & Synchronous \\
\hline
\end{tabular}

TABLE II

MEASURING SCHEDULE

\begin{tabular}{|c|c|c|}
\hline NO & City & Measuring Time \\
\hline 1 & Beijing & May,10,2010-June,7,2010 \\
\hline 2 & Xi'an & August,9,2010- August,16,2010 \\
\hline 3 & Shenzhen & August,5,2010- August,11,2010 \\
\hline 4 & Hefei & August,22,2010- August,28,2010 \\
\hline 5 & Changchun & August,25,2010-August,31,2010 \\
\hline
\end{tabular}

-CDMA2000: CDMA2000 is a family of 3G mobile technology standards, which use CDMA channel access, to send voice, data, and signaling data over wireless networks [15]. The family includes: CDMA2000 1X, CDMA2000 EV-DO Rev. 0, CDMA2000 EV-DO Rev. A, and CDMA2000 EV-DO Rev. B [16]. It was standardized by 3GPP2, offered in North America and South Korea. The successor to CDMA2000 is LTE, part of 3GPP family.

Table 1 illustrates the key parameter comparison of TDSCDMA with WCDMA, CDMA2000.

\section{Measurement Methodology}

The evaluation includes measurement and data analysis. According to the coverage of the $3 \mathrm{G}$ communication network, we choose 5 cities to perform our measurements. We conducted the measurements in the following way:

-Measurement Tool: During the data collecting period, we use the program Pilot Pioneer 4.1.0.1 as the core platform, which is a confirmed measurement tool in the communication field. The user devices comprise Leadcore 8130, Nokia N85, LG KV500, Huawei E180 and ZTE AC8710.

-Measurement Schedule: The main measurement is conducted from May 2010 to August 2010. We were measuring from 8:00 to 18:00 during daytime, so that we could get the information of $3 \mathrm{G}$ network during the busy time. The researching group collects the data of $3 \mathrm{G}$ mobile networking from five typical cities in China. The detailed measuring schedule and location are shown by Table 2 and Fig. 1.

-Measurement Scheme: Based on the different measuring purposes, we imitated the users' behavior to make continuous calls or high speed data downloading during the measuring 


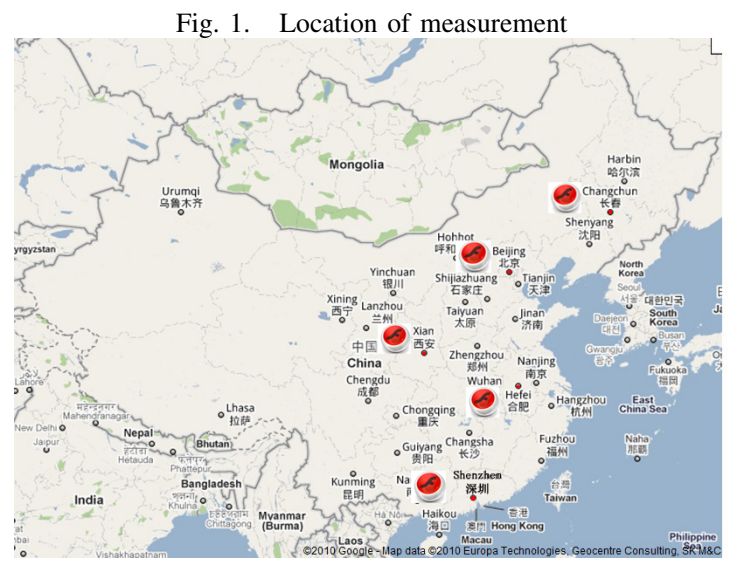

time. The whole measurement can be divided into 2 parts: outdoor measurement and indoor measurement.

Outdoor measurement: Under appropriate route and time, we measured through rate, dropping rate, block rate of all kinds of services in different scenarios. Our approach is the Driver Testing (DT), which collects data during driving on the main street of the city, ring highway, viaduct and airport highway. The secondary main street would be added into measurement route if the length of the main street does not reach the lowest limit.

Indoor measurement: As studies found that $70 \% 3 \mathrm{G}$ data service demands come from indoors [17], the quality of indoor $3 \mathrm{G}$ system is important. The main measurement approach is CQT (call quality test), which tests the call quality during the whole process of the communication at crucial hot spots, such as hotel, business building, station, campus etc. We choose three typical areas to perform our measurement for each hot spot.

\section{Measurement Result and Analysis}

We conducted evaluations on four types of services - voice, video, data, SMS - which cover all kinds of our frequently used applications. The result of service quality evaluation can comprehensively reflect the performance of the $3 \mathrm{G}$ systems.

\section{A. Voice Service}

Voice service is the most original and common service in mobile communication system. We use two indicators, through rate and drop rate, to assess the voice service. During the voice measuring, the user devices are set in $2 / 3 \mathrm{G}$ switch mode. That means if the user cannot connect to TD network due to resource limitation or other reasons, it will automatically switch to GSM network and initiate a call.

1) Through rate: The through rate is a significant indicator to reflect the performance of the communication system. Voice through rate here means the through rate of the whole network. Voice through rate $=(\#$ connections on both GSM\&TD $) /(\#$ initial calls on GSM\&TD).

-TD system performance: Table 3 depicts voice through rate under outdoor and indoor scenarios in five cities. Corresponding to the data in the Table 3, Fig.2 presents the data in
TABLE III

THROUGH RATE OF TD SYSTEM VOICE SERVICE

\begin{tabular}{|c|c|c|c|c|c|}
\hline & Beijing & Xi'an & Shenzhen & Hefei & Changchun \\
\hline Outdoor(\%) & 90.49 & 93.63 & 98.54 & 97 & 95.99 \\
\hline Indoor(\%) & 99.06 & 95 & 100 & 96.67 & 98.33 \\
\hline
\end{tabular}

TABLE IV

COMPARISON OF VOICE SERVICE THROUGH RATE

\begin{tabular}{|c|c|c|c|c|c|}
\hline operator & Beijing & Xi'an & Shenzhen & Hefei & Changchun \\
\hline China Mobile(\%) & 90.49 & 93.63 & 98.54 & 97.00 & 95.99 \\
\hline China Unicom(\%) & 96.15 & 98.71 & 98.61 & 96.85 & 98.72 \\
\hline China Telecom(\%) & 98.46 & 99.69 & 100.00 & 100.00 & 99.75 \\
\hline
\end{tabular}

bar graph. BJ, XA, SZ, HF, CC are short for Beijing, Xi'an, Shenzhen, Heifei and Changchun respectively. As Fig.2 shows, the outdoor through rate is lower than those of indoor scenario, especially in Beijing, whose outdoor through rate is only $90.49 \%$. There are three reasons to explain this phenomenon. First, in outdoor enviroments, the rapid change of environment results in poorer radio condition. We hardly see good through rate under this condition. Second, there is no doubt that changeable locations during the initial calling lead to lower through rate because of the delay of the connection. Third, operators considered the serious attenuation under indoor scenario and established repeaters in the building to enhance the indoor performance. The reason for poor Beijing result is that the designing of measure route is irregular or the measuring area is too remote to be covered by the network.

Fig. 2. Through rate of TD system voice service

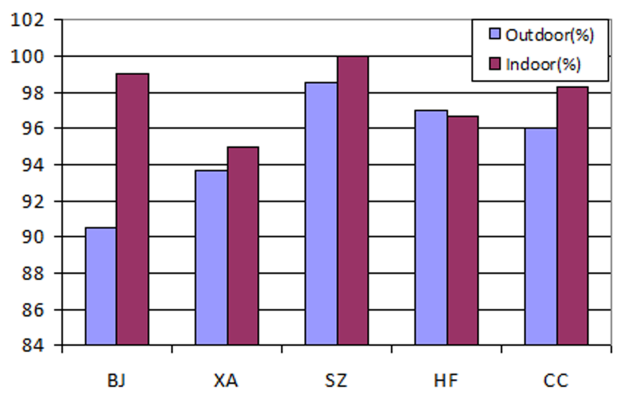

-Comparison: Table 4 illustrates the through rate of voice service under three $3 \mathrm{G}$ networks. At first sight, the through rates in different mobile standards are almost the same. Through studying the data of each city, we can see that China Telecom CDMA2000 has the best performance in this respect.

2) Dropping rate: The definition of dropping is that the channel has been set free without commission from any of the communicating users. Dropping rate is the indicator by which the user can feel the performance of the network directly. In this paper, the dropping rate is for the whole network.

Dropping rate $=(\#$ dropping calls on both GSM\&TD $) /(\#$ initial calls on GSM\&TD). 
TABLE V

DROPPING RATE OF TD SYSTEM VOICE SERVICE

\begin{tabular}{|c|c|c|c|c|c|}
\hline & Beijing & Xi'an & Shenzhen & Hefei & Changchun \\
\hline Outdoor(\%) & 1.23 & 0.2 & 0.44 & 0.69 & 0.3 \\
\hline Indoor(\%) & 0 & 0 & 0 & 0.86 & 0 \\
\hline
\end{tabular}

TABLE VI

COMPARISON OF VOICE SERVICE THROUGH RATE
TABLE VII

VIDEO SERVICE THROUGH RATE OF TD SYSTEM

\begin{tabular}{|c|c|c|c|c|c|}
\hline & Beijing & Xi'an & Shenzhen & Hefei & Changchun \\
\hline Outdoor(\%) & 88.40 & 66.88 & 95.42 & 100 & 97.18 \\
\hline Indoor(\%) & 99.00 & 70 & 93.33 & 98.18 & 96.67 \\
\hline
\end{tabular}

TABLE VIII

COMPARISON OF VIDEO SERVICE THROUGH RATE

\begin{tabular}{|c|c|c|c|c|c|}
\hline operator & Beijing & Xi'an & Shenzhen & Hefei & Changchun \\
\hline China Mobile(\%) & 1.23 & 0.20 & 0.44 & 0.69 & 0.30 \\
\hline China Unicom(\%) & 1.51 & 0.33 & 0.99 & 0.65 & 0.78 \\
\hline China Telecom(\%) & 0.43 & 0.62 & 0.00 & 0.20 & 0.25 \\
\hline
\end{tabular}

\begin{tabular}{|c|c|c|c|c|c|}
\hline operator(\%) & Beijing & Xi'an & Shenzhen & Hefei & Changchun \\
\hline China Mobile(\%) & 88.40 & 66.88 & 95.42 & 100.00 & 97.18 \\
\hline China Unicom(\%) & 90.96 & 96.03 & 99.39 & 98.72 & 100.00 \\
\hline
\end{tabular}

-TD system performance: The voice dropping rates in five cities are shown in Table 5. Except Hefei, we find that the outdoor dropping rate is far higher than indoor dropping rate. The reason is mentioned above, driving test in outdoor environment is affected by the surroundings easily. Since the indoor environment is simper, the indoor dropping rate is really low, even falls to 0. As Fig. 3 shows, there is zero dropping rate in almost all the indoor measurement except Hefei. Because of the high interference in Hefei train station, one drop appeared during the indoor measurement. So the total dropping rate is approximate $0.8 \%$.

Fig. 3. Dropping rate of TD system voice service

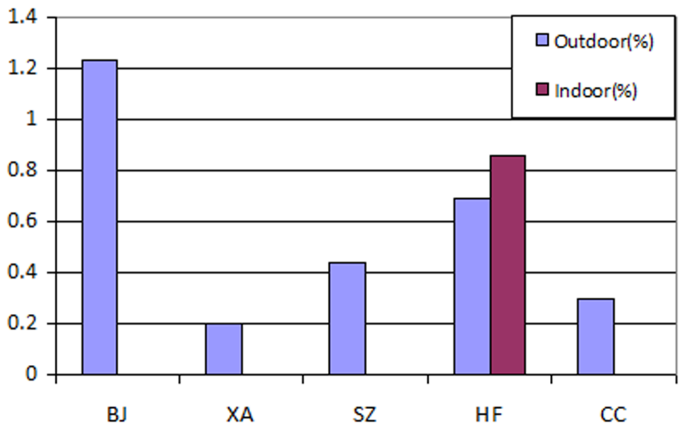

-Comparison: Table 6 shows the comparison of voice dropping rate under 3 standards. Thanks for owning CDMA network, China Telecom CDMA2000 has the lowest dropping rate, compared with TD and WCDMA. China Mobile TD network and China Unicom WCDMA have similar result.

\section{B. Video Service}

Video service is video and audio transmission service for real-time communication on wireless network. It allows users to enjoy video and audio transmissions anywhere and anytime.

1) Through rate: The connections of the video can be divided into two types: connections in circuit domain and connections in video domain. The following results are all taken from the video domain. The definition of video through rate is:
Video through rate $=(\#$ video service connection in $\mathrm{TD}$ network)/ (\# initial video calls in TD network).

-TD system performance: Table 7 displays the video through rate under indoor and outdoor conditions. Unlike the voice service, the rate of indoor and outdoor are close in the same city. Fig.4 shows that Xi' an conspicuously has the worst performance of through rate among all the five cities, with the total rate less than $90 \%$. The main reason for it is that no video service is provided in Xi' an train station, and it causes almost all the failures in videophone connection.

Fig. 4. Video service through rate of TD system

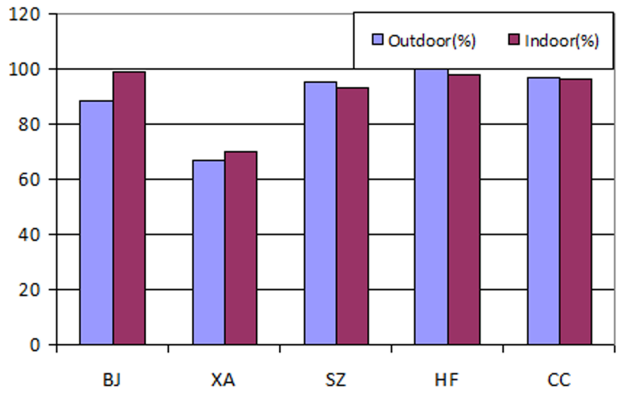

-Comparison: Table 8 displays the video through rate under TD-SCDMA and WCDMA. As the table shows, except Xi' an and Hefei, the China Unicom through rate of video service is slightly higher than China Mobile's. The difference between the two standards is not too much. The unpredictable result of $\mathrm{Xi}$ 'an is still due to the Xi' an train station problem.

2) Dropping rate: Videophone service, combining video and audio, has higher requirement for the user device and network. The video call may fail if the system does not meet any one of the requirements. At this time, the video call will fall back to voice call with the permission of the user. This kind of dropping discontinues video or audio communications. Video dropping rate $=(\#$ video call dropping $) /(\#$ video call connection).

-TD system performance: Table 9 reveals the specific video through rate in five cities. According to these data, we can draw the bar graph as Fig.5. It manifests that the rate is high for the condition of Beijing outdoor and Hefei indoor, $4.66 \%$ 
TABLE IX

VIDEO SERVICE THROUGH RATE OF TD SYSTEM

\begin{tabular}{|c|c|c|c|c|c|}
\hline & Beijing & Xi'an & Shenzhen & Hefei & Changchun \\
\hline Outdoor(\%) & 4.66 & 0.94 & 2.01 & 0 & 0.36 \\
\hline Indoor(\%) & 1.05 & 0 & 0 & 5 & 2.54 \\
\hline
\end{tabular}

TABLE X

COMPARISON OF VIDEO SERVICE DROPPING RATE

\begin{tabular}{|c|c|c|c|c|c|}
\hline operator & Beijing & Xi'an & Shenzhen & Hefei & Changchun \\
\hline China Mobile(\%) & 4.66 & 0.94 & 2.01 & 0.00 & 0.36 \\
\hline China Unicom(\%) & 0.00 & 0.00 & 0.31 & 0.00 & 0.32 \\
\hline
\end{tabular}

and $5 \%$ respectively. The reason is the wireless environment changed unpredictably under these two conditions.

Fig. 5. Video service through rate of TD system

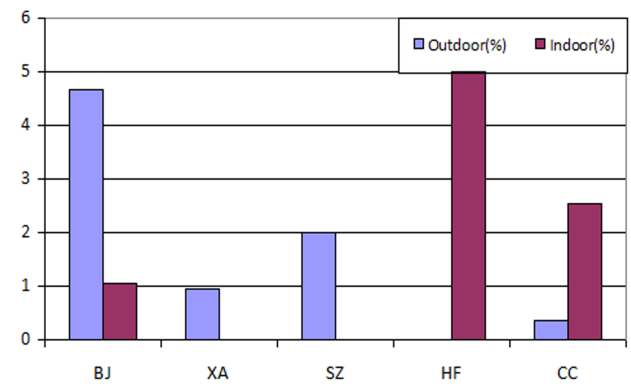

-Comparison: Here, we compare China Mobile dropping rate of video call with China Unicom's. We can see from Table 10 that the dropping rate in WCDMA network is lower than it is in TD-SCDMA, especially in Beijing. This obvious phenomenon can be attributed to the coverage of the 2 standard systems. Since TD-SCDMA is established as a new $3 \mathrm{G}$ member, the uncompleted $3 \mathrm{G}$ network coverage leads to the dropping of the video call.

\section{Data Service}

TD-SCDMA data service is measured with FTP transmissions. This measurement is done by sending data packets from server to user via HSPA and we measure the speed of downloading. The main factors to affect the download rate are: technology of system, resource allocation, wireless environment, scenario, user distribution and service type. Here, we prescribe that the sending bit rate and packet size adopted in our measurement are $2048 \mathrm{kbps}$ and $80 \mathrm{M}$. After the TD user makes a request of HSDPA downloading, we keep the downloading process for five minutes for each measurement location.

During the downloading, if there is sufficient HSDPA resource, HSDPA resources could be allocated to user with higher priority, otherwise the resources defined as PS384K of R4 or GPRS/EDGE resources of $2 \mathrm{G}$ may be allocated.

-TD system performance: Table 11 shows the speed of HSPA download in five different cities for both outdoor and
TABLE XI

DATA DOWNLOAD RATE OF TD SYSTEM

\begin{tabular}{|c|c|c|c|c|c|}
\hline & Beijing & Xi'an & Shenzhen & Hefei & Changchun \\
\hline Outdoor(kbps) & 420.43 & 899.42 & 787.47 & 794.27 & 788.97 \\
\hline Indoor(kbps) & 534.69 & 1177.55 & 877.49 & 900.41 & 834.67 \\
\hline
\end{tabular}

TABLE XII

COMPARISON OF DATA DOWNLOAD RATE

\begin{tabular}{|c|c|c|c|c|c|}
\hline operator & Beijing & Xi'an & Shenzhen & Hefei & Changchun \\
\hline China Mobile(kbps) & 420.43 & 899.42 & 787.47 & 794.27 & 778.97 \\
\hline China Unicom(kbps) & 2462.73 & 3353.75 & 3466.25 & 3658.60 & 3148.08 \\
\hline China Telecom(kbps) & 717.16 & 843.94 & 898.64 & 1061.90 & 797.86 \\
\hline
\end{tabular}

indoor settings, and the corresponding bar graph is drawn in Fig.6. It turns out that the download rate in indoor environment is $100 \mathrm{kbps}$ higher than it is in outdoor environment. Beijing has the lowest download rate among all the cities. The reason for it is that $6 \%$ of the resource usage for data download is R4/GPRS/EDGE resource, it cuts down the average download rate.

Fig. 6. data download rate of TD system

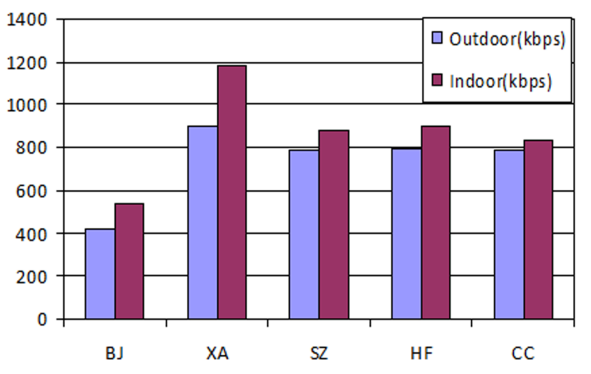

-Comparison: Among the download rate of three 3G network, as Table 12 shows, WCDMA from China Unicom has the fastest download rate, while the worst one is TD system. TD and CDMA2000 have very close performance in the data service. This phenomenon results from the fact that WCDMA-HSDPA has higher capacity than TD-HSDPA, EVDO-Rel.A(belongs to CDMA2000).

Though TD system has the worst performance on data service, the download rate is much higher than previous system. In $2 \mathrm{G}$ systems, GSM provides the data rate of 9,6kbps. In $2.5 \mathrm{G}$, GPRS has maximum data rates of $115 \mathrm{kbps}$ [18], while TD system provides at least $400 \mathrm{kbps}$ in our measurement. It proves that $3 \mathrm{G}$ has better performance on multimedia and high bitrate data services than previous wireless communication system.

\section{SMS}

SMS is a flexible and friendly application for user to use. Users can send their message when the situation is unnecessary or unsuitable to make a phone call. The performance of SMS is another indicator to measure TD network. Here, we obtain 
TABLE XIII

SMS SUCCESS RATE OF TD SYSTEM

\begin{tabular}{|c|c|c|c|c|c|}
\hline & Beijing & Xi'an & Shenzhen & Hefei & Changchun \\
\hline Outdoor(\%) & 93.93 & 94.61 & 96.92 & 88.50 & 97.14 \\
\hline Indoor(\%) & 95.28 & 98.33 & 100 & 93.33 & 98.33 \\
\hline
\end{tabular}

TABLE XIV

COMPARISON OF SMS SUCCESS RATE

\begin{tabular}{|c|c|c|c|c|c|}
\hline operator & Beijing & Xi'an & Shenzhen & Hefei & Changchun \\
\hline China Mobile(\%) & 93.93 & 94.61 & 96.92 & 88.50 & 97.14 \\
\hline China Unicom(\%) & 94.34 & 94.85 & 97.28 & 90.51 & 96.19 \\
\hline
\end{tabular}

the following statistical success rate of $\mathrm{p} 2 \mathrm{p}$ short message reception in outdoor and indoor environments in five cities. Success rate $=(\#$ received $\mathrm{msgs}) /(\#$ sent $\mathrm{msgs})$

-TD system performance: From Table 13 and Fig. 7, we can see the success rate of outdoor is lower than it is under indoor condition. That means the performance of indoor SMS is more satisfactory. Except in Hefei, SMS success rate reaches above $94 \%$ in the other 4 cities, while Hefei only has a low average success rate at $90 \%$. This unexpected phenomenon needs further investigation.

Fig. 7. SMS success rate of TD system

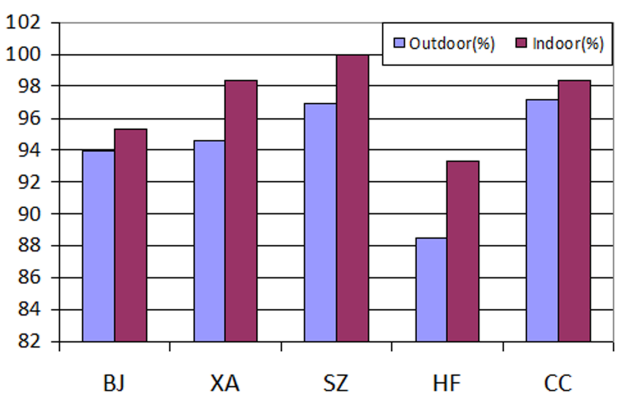

-Comparison: Table 14 presents the comparison of SMS service under two standards. From the information in the table, we can conclude that the results of TD and WCDMA network are close in terms of SMS success rate in most of the cities. Except Hefei, the average SMS success rate of all cities are more than $93 \%$. But as a non-real-time service, this success rate is not satisfactory for the users. Therefore, it is necessary for us to improve SMS performance in further studies.

\section{CONCLUSION}

We have performed an empirical study on the $3 \mathrm{G}$ cellular system performance in five cities in China. The measurement result is presented in this paper. By analyzing these data, we have got some new findings which may be helpful to improve $3 \mathrm{G}$ communication system, especially TD-SCDMA. It helps us to have a better understanding of $3 \mathrm{G}$, which can then be used to corroborate $3 \mathrm{G}$ networks as a foundation for CPNSs.

For further study, we plan to conduct measurement in other cities to get more data of $3 \mathrm{G}$ mobile system performance.
The measurement will not only include more services, but also more indicators, such as the coverage, handoff rate and time, etc. We believe these efforts can further validate or refine our understanding, and help build more robust and dynamic CPNSs.

\section{REFERENCES}

[1] "Cyber-physical systems". Program Announcements \& Information. The National Science Foundation, 4201 Wilson Boulevard, Arlington, Virginia 22230, USA. 2008-09-30. Retrieved 2009-07-21.

[2] Lee, Edward. Cyber Physical Systems: Design Challenges. University of California, Berkeley Technical Report No. UCB/EECS-2008-8. Retrieved 2008-06-07.

[3] http://www.itu.int/ITU-D/imt-2000/DocumentsIMT2000/What_really_ 3G.pdf

[4] http://www.gsmworld.com/technology/3gsm/index.htm

[5] Asheeta Bhavnani, Rowena Won-Wai Chiu, Subramaniam Janakiram. The Role of Mobile Phones in Sustaninable Rural Poverty Reduction. ICT POLICY DIVISION. June 15, 2008

[6] Jun Xia. The third-generation-mobile (3G) policy and deployment in China: Current status, challenges, and prospects. Telecommunications Policy Volume 35, Issue 1, February 2011, Pages 51-63

[7] Bo Li, Dongliang Xie, Wenwu Zhu, Bin Li, Advances on TD-SCDMA in China, IEEE Communications Magazine. January 2005

[8] Shengquan Wang, Dong Xuan, Riccardo Bettati and Wei Zhao, Providing Absolute Differentiated Services for Real-Time Applications in Static-Priority Scheduling Networks, IEEE/ACM Transactions on Networking (ToN), Vol 12, No. 2, April 2004, pp. 326-339.

[9] Ionut Trestian,Supranamaya Ranjan, Aleksandar Kuzmanovic, Antonio Nucci.Measuring Serendipity: Connecting People, Locations and Interests in a Mobile 3G Network.IMC09, Chicago,USA. 2009

[10] Pralhad Deshpande, Xiaoxiao Hou, Samir R. Das.Performance Comparison of $3 G$ and Metro-Scale WiFi for Vehicular Network Access.IMC10, Melbourne, Australia, 2010.

[11] Fung Po Tso, Jin Teng, Weijia Jia and Dong Xuan, Mobility: A DoubleEdged Sword for HSPA Networks, in Proc. of ACM International Symposium on Mobile Ad Hoc Networking and Computing (MobiHoc), Sept. 2010.

[12] Kammerlander,K., Benefits and Implementation of TD-SCDMA, Communication Technology Proceedings 2000. WCC-ICCT2000, 6 Aug2000, 1012-1016 vol.2

[13] Dahlman E., Beming P., Knutsson J., Ovesjo F., Persson M., Roobol C..WCDMA-the radio interface for future mobile multimedia communications.Vehicular Technology, IEEE Transactions. Nov 1998

[14] Draft summary minuutes, decisions and actions from 3GPP Organizational Partners Meeting\#6, Tokyo, 9 October 2001. Pp.7.

[15] Douglas N. Knisely, Sarath Kumar, Subhasis Laha, Sanjiv Nanda. Evolution of Wireless Data Services: IS-95 to cdma2000.IEEE Communications Magazine. October 1998

[16] http://www.cdg.org/technology/cdma2000.asp

[17] G. Mansfield, Femtocells in the US Market -Business Drivers and Consumer Propositions, FemtoCells Europe, ATT, London, U.K., June 2008.

[18] http://www.mobilein.com/GPRS.pdf 